\title{
COMMUNICATIONS AND DISCUSSIONS
}

\section{MENTALITY TESTS: A SYMPOSIUM}

(Concluded from the May number.)

1. The point scale method versus the age-grade method. I find myself unable to concede to the point scale method a single one of the numerous advantages which have been claimed for it. I do not see that the Yerkes-Bridges point scale, in particular, furnishes any real contrast, except in minor and unessential points, to the age-grade method of Binet. The point scale is itself an age-grade method, for its results have no known or ascertainable significance until they have first been interpreted in the light of age norms and in terms of the intelligence quotient.

Ever if a point scale were desirable I do not believe it can be shown that the manner of deriving the Yerkes-Bridges scale is either logically or psychologically defensible. From the psychological point of view, especially, the arbitrary assignment of point values seems to me to have been objectionable in several respects. A point scale which is to possess any serious claim to superiority must be framed with some regard for the equivalence of points, and as far as this desideratum is concerned $I$ believe that a more valid point scale than any yet available could be derived in less than two minutes by merely assigning two points to each test in a properly revised Binet scale, or for that matter by simply using the intelligence quotients derived by the Binet method as points for a point scale. The logical fallacies of the Yerkes-Bridges scale and the possibility of devising a really valid equalpoint scale will be treated at some length in a forthcoming article by a Stanford University student.

All of us, doubtless, are equally desirous that any intelligence scale, old or new, shall stand or fall according to its intrinsic merit. A comparative evaluation of two intelligence scales, however, is no light matter. It requires more than off-hand criticism, more even than a little investigation or two. The proposal to decide the matter "by agreement" can of course not be taken seriously. Scientific disputes were settled that way by the churchmen of the Middle Ages, but the method is a little out of date now. When suitable revisions of the 
Binet scale have been thoroughly tried out alongside of newer scales I predict there will be an end to the proposals to "scrap" the method as obsolete. Anyway, progress in this field will come, not from psychological decree, but from the demonstrable results of scientific research.

Present work at Stanford University. Until recently our time here has been taken up with work on the Stanford revision of the Binet scale. This has now been completed and will appear shortly in a monograph and a Guide to be published separately. The monograph will be devoted to an analysis of the results of 1,000 tests of unselected children, and will contain the following chapters: The distribution of intelligence; The validity of the intelligence quotient; Sex differences; The relation of intelligence to social status; The relation of intelligence to school success; Considerations relating to the formation of an intelligence scale.

The Guide, which will be issued by Houghton Mifflin Co., will contain an untechnical exposition of the Binet method and an amplified guide for the use and interpretation of the individual tests. The chapters are as follows: I. The uses of intelligence tests; II. The sources of error in judging intelligence; III. The Binet-Simon method; IV. The nature of the Stanford Revision; V. An analysis of 1,000 intelligence quotients; VI. The significance of various intelligence quotients; VII. The reliability of the Binet scale; VIII. General directions; IX-XX. Guide for use of the individual tests. The latter volume will appear abòut June 1st.

At present we are at work on a new scale. Some 20 sets of serial tests of widely varying nature have been assembled. In its present form this material is so extensive as to require from three to five sittings with each subject. A preliminary try-out is now in progress, from the results of which we hope to be able to select enough tests out of the entire mass to make one or possibly two or even three scales. The plan of the investigation is one that will permit the use of the same results for the formation of three types of scales-one like that of Binet, an equal-point scale for general intelligence, and several serial scales for separate functions. Since all of these are to be based on the same test results, it will be possible to ascertain the relative value of the different scales so derived.

Apart from this we are using the Stanford revision in studies of racial differences, of the growth rate, and of intelligence of twins, delinquents, and superior children. 
The oulook for mentality tests. I believe that mentality testing wilf continue for some years to be mainly intelligence testing. At present this is the field which offers the largest returns for a given expenditure of effort. Moreover, after further exploration in this line we shall have a more secure basis for mentality testing of the more inclusive sort. We must not forget, too, the overtowering importance of intelligence as a factor in determining the individual's educational, social, and vocational possibilities. Largely for lack of the guidance which intelligence tests can give us, our education is a mixture of guesswork and patch-work; the data gathered by the use of pedagogical scales are equivocal; social classes and races are misunderstood and misjudged; and attempts at political and social reform go wide of the mark. I believe that social and racial psychology in particular will soon have to be rewritten in the light of results which will be secured by the use of intelligence tests.

Another important problem, perhaps the most urgent of those which promise early solution, is the determination of the growth rate. It is on this that the possibility of predictions wholly depends. I believe that in the near future it will be possible, after a brief test of even a young child, to forecast the later course of such child's mental development with a degree of accuracy as yet unthought of.

Who shall use intelligence scales? Although I am fully in accord with the recent action of the American Psychological Association in the attempt to discourage the use of intelligence tests for strictly diagnostic and research purposes by persons without extensive psychological training, I am no less equally convinced that there is no reason why every prospective teacher should not be taught how to use the Binet or some other system of standardized intelligence tests for the purpose of arriving at a better understanding of her pupils than would otherwise be possible. The technical knowledge and skill necessary for this purpose can, under the proper instruction, be acquired in ten weeks by anyone who has intelligence enough to teach school. It goes without saying that such a brief course of training does not fit one to use the tests for purposes of research or serious diagnosis, but my own experience has taught me that this is sufficient to enable the teacher to get results which, with ordinary school children, do not differ materially in one case out of twenty from those secured by the most highly trained expert. I think we must agree that a good deal which has been said $a$ propos of psycho-clinical expertness (whatever that is) as a prerequisite for using the Binet 
scale is hollow buncombe. As a matter of fact, there is no argument in favor of limiting the use of intelligences tests to trained psychologists which does not apply equally well in the case of pedagogical tests like those of Courtis, Ayres, Thorndike, etc. These tests, fortunately for education, teachers are specifically urged to make use of. No one has sought to envelop them in tabus for the glorification or personal advantage of the élite who have been initiated into their mysteries. Let us abandon pretense and take the same common sense attitude toward the Binet scale. When we have taken this attitude I believe we shall find that to understand and apply a well planned and well written Binet guide is as much within the power of the average teacher or school principal as it is to decipher and apply with technical correctness any reasonably complete set of directions for current pedagogical tests. Certainly there should be nothing in such a guide to compare in difficulty with the puzzling features of the Courtis manual.

Stanford University.

Lewis M. Terman.

Ten years spent chiefly in making mental inventories of men, women and children of many sorts have emphasized for me several facts and problems as important to an efficient clinical application of psychological data. I here present them, necessarily rather tersely, for the consideration of the readers of the symposium.

1. Mental tests are of uše in appraising an individual only when the one using them is able to psychologize in reference to the results, only when he is able to translate simple responses into terms of mental process involved, only when he is able to avoid confusing mental content with mental process.

This limitation carries with it the implication that the appraiser of the individual must make the tests himself, or at least watch the procedure, as a response can be fairly judged only as a part of the whole circumstance which produced it.

2. Mental tests are of use in appraising an individual only when a rapport is established between the experimenter and the subject. If the subject is intimidated or repelled by the examiner or by the surrounding conditions a true estimate of his ability can not be made. On this account rapid examinations for diagnostic purposes are unjustifiable.

These two facts are not grasped by that large body of public spirited men and women who are making a sincere effort to evaluate the con- 